\title{
A randomized controlled clinical trial evaluating the effect of Trigonella foenum-graecum (fenugreek) versus glibenclamide in patients with diabetes
}

\author{
Rania A Najdi ${ }^{1}$, Magda M Hagras², Fatemah O Kamel ${ }^{1}$, Rania M Magadmi ${ }^{1}$
}

1. Pharmacology Department, Faculty of Medicine, KAU, Jeddah, Saudi Arabia

2. Pharmacology department, Faculty of Medicine, Suez Canal University, Egypt

Email addresses: Rania A Najdi (rania.magadmi@yahoo.com); Magda M Hagras, MBBS PhD (Magyhagras@hotmail.com); Fatemah O Kamel, MBBS MSc PhD (fokamel@kau.edu.sa); Rania M Magadmi,MBBS PhD (rmagadmi@ kau.edu.sa).

\begin{abstract}
Background: Herbal medicines long have been used in the management of diabetes mellitus (DM).

Objective: This study was conducted to ascertain if fenugreek compared with glibenclamide had any impacts on controlling blood glucose in patients with uncontrolled type II DM on conventional therapy.

Methods: A total of 12 patients with uncontrolled DM and on metformin were recruited and divided into two groups. Patients in group 1 received $2 \mathrm{~g}$ fenugreek per day, whereas those in group 2 received glibenclamide $5 \mathrm{mg}$ once daily. The impacts of fenugreek on the glycemic control and lipid profile were measured before initiation of the regimen and then after 12 weeks.

Results: Only 9 of the 12 study participants completed the study. Fenugreek at $2 \mathrm{~g} /$ day caused an insignificant drop in fasting blood glucose $(\mathrm{P}=0.63)$, but the fasting insulin level increased significantly $(\mathrm{P}=0.04)$. The ratio of high- to low-density lipoprotein was significantly decreased from before to after treatment $(\mathrm{P}=0.006)$. Fenugreek did not cause any notable adverse impacts on hepatic and renal functions throughout the study.

Conclusion: Fenugreek could be used as adjuvant therapy to anti-diabetic drugs to control blood glucose, and further studies are needed.

Keywords: Trigonella foenum-graecum (fenugreek), glibenclamide, diabetes.

DOI: https://dx.doi.org/10.4314/ahs.v19i1.34

Cite as: Najdi RA, Hagras MM, Kamel FO, RM M. A randomized controlled clinical trial evaluating the effect of Trigonella foenum-graecum (fenugreek) versus glibenclamide in patients with diabetes. Afri Health Sci. 2019;19(1). 1594-1601. https:/ / dx.doi.org/10.4314/abs.v19i1.34
\end{abstract}

\section{Introduction}

Diabetes mellitus (DM) is a heterogeneous condition with features of altered cell metabolism.

In 2014, World Health Organization reported that over 400 million people were diabetic worldwide ${ }^{1}$. DM is more
Corresponding author:
Rania M Magadmi,
Pharmacology Department,
Faculty of Medicine,
KAU, P.O. Box 42751,
Jeddah 21551 Saudi Arabia;
Tel: +966126401000 ext: 23078/40252;
Email:rmagadmi@kau.edu.sa

common in developed compared with developing countries due to nutritional and lifestyle factors ${ }^{2}$. The incidence of diabetes has been on the rise probably due to lifestyle changes that encourage sedentary lifestyles, lack of exercise, and aging. ${ }^{3}$. Uncontrolled DM increases the risks of morbidity and/or mortality from DM complications.

Management of diabetes usually is complex following its complex pathophysiology and devastating complications. Patients with diabetes are often put on a treatment plan that encompasses health and wellness teaching, nutritional education, as well as encouraging adherence to the established therapeutic plan. The guidelines for management of type $2 \mathrm{DM}$ recommended metformin as the first line drug when diet and exercise do not work. However, 
most anti-diabetic drugs are expensive, and some have adverse effects. Thus, there is a need for new therapies with fewer side effects and better cost-effectiveness. Medicinal plants have been used in attempts to control DM. Among many plants, Trigonella foenum-graecum (fenugreek) has been used traditionally in the management of blood glucose levels in patients with type $2 \mathrm{DM}$ in many Arabic countries ${ }^{4-6}$. The anti-diabetic effect of fenugreek has been confirmed in patients with diabetes ${ }^{7,8}$. From the in vivo studies, it has been suggested that fenugreek controls blood sugar levels mainly by inhibition of carbohydrate digestion and absorption, and enhancement of peripheral insulin action ${ }^{7}$. Nevertheless, there is not enough evidence of fenugreek's effect on patient with diabetes. Thus, an open-labeled controlled study was conducted on mild-to-moderate type $2 \mathrm{DM}$ to evaluate the impacts of fenugreek seeds.

\section{Methods \\ Study design}

This interventional open-label randomized controlled allocation concealed trial evaluated the efficacy of fenugreek versus glibenclamide in controlling blood glucose levels in patients with uncontrolled diabetes.

\section{Methods}

This study included 12 randomly selected patients with type $2 \mathrm{DM}$ receiving metformin as per the hospital protocol. The subjects were recruited from the Department of Medicine in King Abdulaziz University Hospital in Jeddah between October 2010 and April 2012. The study protocol was approved by the King Abdulaziz University Hospital Independent Ethics Committee Center before enrollment of any subject, and informed consent was obtained before randomization. The study included 12 patients with diabetes of both sexes, aged more than 18 years. Patients with type $2 \mathrm{DM}$ and a fasting blood glucose (FBG) level greater than or equal to $140 \mathrm{mg} / \mathrm{dL}$ of blood with no notable complications, hemoglobin A1c (HbA1c) levels greater than 7\%, and those receiving an metformin with a history of poorly controlled serum glucose were included in the study.

Exclusion criteria were patients who were already on sulfonylurea drugs, patients who could not provide informed consent for participation; patients on medications, such as cortisone, that affect serum glucose levels; pregnant and lactating patients; and patients with complications arising from diabetes. Also excluded from the study were patients with type $1 \mathrm{DM}$, patients with mental illness, patients treated with insulin therapy, or those with other conditions, such as gastrointestinal tract, renal, hepatic, cardiovascular, and endocrine conditions that could affect the absorption and metabolism of fenugreek.

The candidates were allocated randomly into two groups using a computer-generated randomization list. To ensure concealment, opaque sealed envelopes were numbered, and each contained a card with the allocation information. A study nurse was assigned to open envelopes to allocate patients into two groups. In group 1, patients received $2 \mathrm{~g}$ fenugreek (Fenugreek; GNC, Pittsburgh, PA, USA) spread over the day as $500 \mathrm{mg}$ (one capsule) after breakfast, $1000 \mathrm{mg}$ (two capsules) after lunch, and $500 \mathrm{mg}$ (one capsule) after dinner. This dose is as suggested by GNC company for over-the-counter use. The study participants were asked to take the capsules post-prandially together with their medications. In group 2, patients received $5 \mathrm{mg}$ glibenclamide once daily (OD) (Daonil; Aventis Pharma, Midrand, South Africa) ${ }^{9}$. Both groups were asked to continue on their metformin regimen and take fenugreek/ glibenclamide as an adjuvant to metformin.

Following randomization, the subjects were scheduled to visit the clinic at 0 and 12 weeks from the commencement of the research. During every visit, anthropometric measurements of body weight and height were measured before (week 0) and after (week 12) the trial period. The primary endpoint was HbA1c (time frame, three months), whereas the secondary endpoints were plasma glucose concentration and plasma lipid profiles (cholesterol, triglyceride, high- [HDL] and low- [LDL] density lipoprotein). Body mass index (BMI; time frame, three months) was measured at several visits during the study. Visit 1 was scheduled for information, screening, and informed consent signature, visit 2 for randomization and first drug issue, and visit 3 was scheduled 12 weeks later. The outcomes were estimated at the time of enrollment in the study and then after three months. The results of the inquiry then were compared at the end of 12 weeks of study.

The assessment encompassed laboratory investigations, including FBG. The levels of HbA1c were determined before the study and then at the end of week 12. A 
Dextrostix automatic biochemistry analyzer (Beckman-Coulter, Brea, CA, USA) was used to estimate the blood glucose levels through the glucose oxidase method. $\mathrm{HbA} 1 \mathrm{c}$, on the other hand, was estimated by an automatic HbA1c apparatus (Bio-Rad Laboratories, Hercules, CA, USA).

\section{Rejection and dropout}

Patients were rejected if they were inconsistent with the inclusion criteria. Those who had poor compliance were dropped from the study, as well as individuals who suffered immense adverse effect or who withdrew from the study at their discretion. Statistical analysis was conducted in accordance with the intention to treat (ITT) analysis.

\section{Statistical analysis}

The data were analyzed with the Statistical Program SPSS (Statistical Package for Social Science; SPSS, Inc., Chicago, IL, USA), version 20. Descriptive statistics comprised the mean and standard deviation (SD). Post- and pre-treatment data were compared using the paired t-test. Investi- gational groups were compared regarding the quantitative variables using Student's t-test for independent samples as normal distribution ensured. A probability value (P value $)<0.05$ was considered significant with $95 \%$ confidence interval (CI). Biostatistics was performed according to ITT analysis. Every procedure in the study used two-sided tests with $\mathrm{a}=0.05$, and $\mathrm{P}<0.05$ was deemed substantially different.

\section{Results}

A total of 12 patients were recruited to the study, with a disease course of $4.8 \pm 2.1$ years. Six patients (mean age, $50.8 \pm 11.3$ years) randomized to receive fenugreek (group 1 ) and 6 (mean age, $51.5 \pm 10.1$ years) randomized to receive glibenclamide (group $2 ; \mathrm{P}=0.92$ ). One patient was withdrawn from group 1 , whereas 2 were withdrawn from group 2 due to changing medication or personal problems. All participants were followed until the end of the study, and their data were included in the statistical analysis. BMI was $28.2 \pm 2.1$ in group 1 and $27.4 \pm 2.2$ in group 2. There was no significant difference between the groups regarding age or BMI (P > 0.05; Table 1).

\section{Table 1: Characteristics of the study patients receiving fenugreek or glibenclamide at baseline}

\begin{tabular}{llll} 
& Fenugreek & Glibenclamide & $\boldsymbol{P}$ value \\
\hline Age & $50.8 \pm 11.3$ & $51.5 \pm 10.1$ & 0.92 \\
\hline Body weight $(\mathbf{k g})$ & $81.3 \pm 7.1$ & $80.9 \pm 7.5$ & 0.94 \\
\hline $\begin{array}{l}\text { BMI } \\
\left.\text { Body weight } \mathbf{( k g ) / h e i g h t ~} \mathbf{( m}^{\mathbf{2}}\right)\end{array}$ & $28.2 \pm 2.1$ & $27.4 \pm 2.2$ & 0.6 \\
\hline
\end{tabular}

At the end of the study, the mean patient weight was $78.78 \pm 8.23$ and $80.60 \pm 7.3 \mathrm{~kg}$ in the groups 1 and 2 , respectively, whereas the BMI was $27.32 \pm 2.12$ and 27.3 \pm 1.31 , respectively, which was not statistically significant compared with the baseline values $(\mathrm{P}>0.05)$.

There was no significant statistical difference between the two groups concerning the following biochemical and hematological reactions at baseline (Table 2): Aspartate aminotransferase (AST), alanine aminotransferase (ALT), creatinine, uric acid, blood urea nitrogen (BUN), alkaline phosphatase, bilirubin, hemoglobin, hematocrit, red cell count, mean corpuscular volume (MCV), mean corpuscular hemoglobin $(\mathrm{MCH})$, mean corpuscular hemoglobin concentration (MCHC), leukocyte count, basophils, eosinophils, lymphocytes, monocytes, and platelet count. 
Table 2: Biochemical and hematological investigations of the study patients receiving fenugreek or glibenclamide at baseline

\begin{tabular}{|c|c|c|c|}
\hline & Fenugreek $(n=5)$ & Glibenclamide $(n=4)$ & $P$ value \\
\hline AST (U/L) & $17.8 \pm 2.94$ & $17.75 \pm 1.7$ & 0.21 \\
\hline $\operatorname{ALT}(\mathbf{U} / \mathbf{L})$ & $24.8 \pm 5.4$ & $24.75 \pm 2.98$ & 0.98 \\
\hline Alkaline phosphatase (U/L) & $63.6 \pm 14.9$ & $76.2 \pm 16.74$ & 0.27 \\
\hline Creatinine (mg/dL) & $0.72 \pm 0.14$ & $0.67 \pm 0.0 .28$ & 0.76 \\
\hline BUN (mg/dL) & $14.20 \pm 3.34$ & $13.25 \pm 7.27$ & 0.80 \\
\hline Uric acid (mg/dL) & $5.52 \pm 1.25$ & $5.05 \pm 1.66$ & 0.64 \\
\hline Bilirubin (mg/dL) & $0.42 \pm 0.16$ & $0.35 \pm 0.10$ & 0.48 \\
\hline Hemoglobin (mg/dL) & $11.77 \pm 6.47$ & $13.26 \pm 1.41$ & 0.71 \\
\hline Hematocrit (\%) & $48.20 \pm 6.01$ & $41.55 \pm 3.86$ & 0.09 \\
\hline Red cell count (mil/cmm) & $5.44 \pm 0.74$ & $4.70 \pm 0.46$ & 0.12 \\
\hline MCV (fL) & $88.74 \pm 3.93$ & $88.57 \pm 6.30$ & 0.96 \\
\hline MCH (Pg) & $27.68 \pm 1.29$ & $27.87 \pm 2.4$ & 0.88 \\
\hline MCHC (gm/dL) & $31.20 \pm 0.62$ & $31.47 \pm 0.45$ & 0.48 \\
\hline Leukocyte count (cmm) & $8480.18 \pm 2684.46$ & $5925.00 \pm 693.27$ & 0.13 \\
\hline Basophils (0-2\%) & $0.00 \pm 0.00$ & $0.00 \pm 0.00$ & NS \\
\hline Eosinophils (0-6\%) & $1.80 \pm 0.44$ & $2.00 \pm 0.00$ & 0.40 \\
\hline Lymphocytes (15-45\%) & $35.40 \pm 9.78$ & $38.25 \pm 8.05$ & 0.65 \\
\hline Monocytes (4-9\%) & $2.00 \pm 0.00$ & $2.25 \pm 0.50$ & 0.29 \\
\hline Platelet count $(\mathrm{cmm})$ & $311.60 \pm 76.88$ & $377.50 \pm 107.45$ & 0.31 \\
\hline
\end{tabular}

Values were mean $\pm \mathrm{SD}$, significant level was considered at $P<0.05$. Patients in both groups were on metformin. AST: Aspartate aminotransferase, ALT : alanine aminotransferase, BUN: blood urea nitrogen, MCV: mean corpuscular volume, MCH: mean corpuscular hemoglobin, MCHC: mean corpuscular hemoglobin concentration.

The primary outcome measures were FBG level, insulin level HbA1c, and homeostatic model assessment for insulin resistance (HOMA-IR), whereas secondary outcome measures were lipid profile (HDL, LDL, triglycerides, total cholesterol, and HDL/LDL ratio). As shown in Table 3, all parameters remained as before except for fasting insulin level, which showed an increase in HOMA-IR in group 1 from $6.98 \pm 1.78$ to $9.62 \pm 3.16 \mu \mathrm{U} / \mathrm{mL}(95 \%$ CI, $0.10-5.17 ; \mathrm{P}=0.04)$ and an increase in the HDL/
LDL ratio in group 1 from $0.38 \pm 0.08$ to $0.50 \pm 0.22$ (95\% CI, 0.243-0.78; $\mathrm{P}=0.006$ ).

Administration of fenugreek for three months in addition to conventional therapy decreased the FBG, although this decrease was not significant. Furthermore, HbA1c decreased but did not reach normal values (6.2). On the other hand, administration of glibenclamide in addition to the conventional therapy metformin for three months non-significantly decreased the FBG, HOMA-IR, and HbA1c. 
Table 3: The effect of fenugreek and glibenclamide on blood glucose and lipid profile before and after treatment.

Fenugreek (2 g/dL) Glibenclamide (5 mg OD)

$(n=5)$

\begin{tabular}{|c|c|c|c|c|c|c|}
\hline & $\begin{array}{l}\text { Pre- } \\
\text { treatment }\end{array}$ & $\begin{array}{l}\text { Post- } \\
\text { treatment }\end{array}$ & $\begin{array}{l}95 \% \text { CI } \\
\text { (P value) }\end{array}$ & $\begin{array}{l}\text { Pre- } \\
\text { treatment }\end{array}$ & $\begin{array}{l}\text { Post- } \\
\text { treatment }\end{array}$ & $\begin{array}{l}95 \% \text { CI } \\
\text { (P value) }\end{array}$ \\
\hline FBG (mg/dL) & $\begin{array}{l}206.60 \\
\pm 101.78\end{array}$ & $\begin{array}{l}191.4 \\
\pm 71.05\end{array}$ & $\begin{array}{l}-97.27- \\
66.87 \\
(0.63)\end{array}$ & $\begin{array}{l}138.00 \\
\pm 34.73\end{array}$ & $\begin{array}{l}122.75 \\
\pm 28.72\end{array}$ & $\begin{array}{l}-36.8-6.34 \\
(0.11)\end{array}$ \\
\hline $\begin{array}{l}\text { Fasting insulin } \\
\text { level }(\mu \mathrm{U} / \mathrm{mL})\end{array}$ & $\begin{array}{l}6.98 \\
\pm 1.78 \\
\end{array}$ & $\begin{array}{l}9.62 \\
\pm 3.16 \\
\end{array}$ & $\begin{array}{l}0.10-5.17 \\
(0.04)\end{array}$ & $\begin{array}{l}7.60 \\
\pm 1.29 \\
\end{array}$ & $\begin{array}{l}8.05 \\
\pm 1.75 \\
\end{array}$ & $\begin{array}{l}-1.28-0.38 \\
(0.186)\end{array}$ \\
\hline HOMA-IR & $\begin{array}{l}4.21 \\
\pm 1.08\end{array}$ & $\begin{array}{l}3.53 \\
\pm 2.23\end{array}$ & $\begin{array}{l}-1.47-2.84 \\
(0.42)\end{array}$ & $\begin{array}{l}2.63 \\
\pm 0.28\end{array}$ & $\begin{array}{l}2.23 \\
\pm 0.22\end{array}$ & $\begin{array}{l}-0.93-0.12 \\
(0.09)\end{array}$ \\
\hline HbA1c (\%) & $\begin{array}{l}9.04 \\
\pm 1.28\end{array}$ & $\begin{array}{l}8.54 \\
\pm 2.10\end{array}$ & $\begin{array}{l}-0.90-1.90 \\
(0.38)\end{array}$ & $\begin{array}{l}7.40 \\
\pm 1.20\end{array}$ & $\begin{array}{l}7.05 \\
\pm 1.13\end{array}$ & $\begin{array}{l}-0.75-0.05 \\
(0.06)\end{array}$ \\
\hline $\begin{array}{l}\text { Cholesterol } \\
\text { (mg/dL) }\end{array}$ & $\begin{array}{l}214.00 \\
\pm 59.74 \\
\end{array}$ & $\begin{array}{l}236.20 \\
\pm 70.35\end{array}$ & $\begin{array}{l}-8.97-53.37 \\
(0.11)\end{array}$ & $\begin{array}{l}191.00 \\
\pm 27.16 \\
\end{array}$ & $\begin{array}{l}186.00 \\
\pm 42.59\end{array}$ & $\begin{array}{l}-33.31-23.31 \\
(0.61)\end{array}$ \\
\hline $\begin{array}{l}\text { Triglyceride } \\
\text { (mg/dL) }\end{array}$ & $\begin{array}{l}225.40 \\
\pm 98.38\end{array}$ & $\begin{array}{l}204.00 \\
\pm 51.02\end{array}$ & $\begin{array}{l}-116.51- \\
73.71 \\
(0.56) \\
\end{array}$ & $\begin{array}{l}134.75 \\
\pm 25.86\end{array}$ & $\begin{array}{l}134.00 \\
\pm 17.56\end{array}$ & $\begin{array}{l}-24.93-23.43 \\
(0.92)\end{array}$ \\
\hline $\begin{array}{l}\text { HDL } \\
(\mathrm{mg} / \mathrm{dL})\end{array}$ & $\begin{array}{l}52.00 \\
\pm 20.11 \\
\end{array}$ & $\begin{array}{l}54.00 \\
\pm 24.28 \\
\end{array}$ & $\begin{array}{l}-5.90-9.90 \\
(0.48)\end{array}$ & $\begin{array}{l}42.80 \\
\pm 6.61 \\
\end{array}$ & $\begin{array}{l}48.00 \\
\pm 7.90 \\
\end{array}$ & $\begin{array}{l}-0.97-11.37 \\
(0.07)\end{array}$ \\
\hline $\begin{array}{l}\text { LDL } \\
(\mathrm{mg} / \mathrm{dL})\end{array}$ & $\begin{array}{l}131.00 \\
\pm 14.87\end{array}$ & $\begin{array}{l}108.25 \\
\pm 31.11\end{array}$ & $\begin{array}{l}-53.00-7.50 \\
(0.09)\end{array}$ & $\begin{array}{l}139.00 \\
\pm 48.20\end{array}$ & $\begin{array}{l}154.80 \\
\pm 72.55\end{array}$ & $\begin{array}{l}-44.20-75.80 \\
(0.50)\end{array}$ \\
\hline $\begin{array}{l}\text { HDL/LDL } \\
\text { (above 0.4) }\end{array}$ & $\begin{array}{l}0.38 \\
\pm 0.08 \\
\end{array}$ & $\begin{array}{l}0.50 \\
\pm 0.22 \\
\end{array}$ & $\begin{array}{l}0.243-0.78 \\
(0.006)\end{array}$ & $\begin{array}{l}0.39 \\
\pm 0.13 \\
\end{array}$ & $\begin{array}{l}0.51 \\
\pm 0.17 \\
\end{array}$ & $\begin{array}{l}-0.23-0.007 \\
(0.06)\end{array}$ \\
\hline
\end{tabular}

Values were mean $\pm \mathrm{SD}$, significant level was considered at 0.05 . FBG: fasting blood glucose, HOMA-IR: homeostatic model assessment for insulin resistance, HbA1c: hemoglobin A1c, HDL: high density lipoprotein,

LDL: low density lipoprotein.

Next, the effects of fenugreek on controlling blood glucose and lipid were compared with those of glibenclamide. Table 4 showed that there was a non-significant lowering of FBG in group 2 compared with group 1. Moreover, there was an insignificant difference between the groups with respect to fasting insulin release.

On the other hand, insulin resistance decreased more significantly in group 2 than in group 1 (HOMA-IR, $2.23 \pm$ 0.22 vs. $3.53 \pm 2.23$, respectively; $95 \% \mathrm{CI}, 0.78-3.48 ; \mathrm{P}=$
0.007). Furthermore, compared with fenugreek, glibenclamide significantly lowered the HbA1c (95\% CI, 0.053.96; $\mathrm{P}=0.04)$ and triglyceride (134.00 \pm 17.56 vs. 204.00 $\pm 51.02 \mathrm{mg} / \mathrm{dL} ; 95 \% \mathrm{CI}, 6.15-133.84, \mathrm{P}=0.036)$ values.

\section{Safety Parameters Comparison}

No significant change was noted before and after therapy in ALT, AST, BUN, and creatinine levels in both groups (P>0.05) (Supplement 1). 
Table 4: Comparison between fenugreek and glibenclamide on blood glucose control and lipid profile after three months of administration of the drug in patients with diabetes.

\begin{tabular}{|c|c|c|c|}
\hline & $\begin{array}{l}\text { Fenugreek }(2 \mathrm{~g} / \mathrm{dL}) \\
(n=5)\end{array}$ & $\begin{array}{l}\text { Glibenclamide (5 mg OD) } \\
(n=4)\end{array}$ & $\begin{array}{l}95 \% \text { CI } \\
(P \text {-value })\end{array}$ \\
\hline FBG (mg/dL) & $\begin{array}{l}191.4 \\
\pm 71.05\end{array}$ & $\begin{array}{l}122.75 \\
\pm 28.72\end{array}$ & $\begin{array}{l}-21.61- \\
158.91 \\
(0.115) \\
\end{array}$ \\
\hline $\begin{array}{l}\text { Fasting insulin level } \\
(\mu \mathrm{U} / \mathrm{mL})\end{array}$ & $\begin{array}{l}9.62 \\
\pm 3.16 \\
\end{array}$ & $\begin{array}{l}8.05 \\
\pm 1.75 \\
\end{array}$ & $\begin{array}{l}-2.003-6.04 \\
(0.27)\end{array}$ \\
\hline HOMA-IR & $\begin{array}{l}3.53 \\
\pm 2.23\end{array}$ & $\begin{array}{l}2.23 \\
\pm 0.22\end{array}$ & $\begin{array}{l}0.78-3.48 \\
(0.007)\end{array}$ \\
\hline HbA1c (\%) & $\begin{array}{l}8.54 \\
\pm 2.10 \\
\end{array}$ & $\begin{array}{l}7.05 \\
\pm 1.13 \\
\end{array}$ & $\begin{array}{l}0.05-3.96 \\
(0.04)\end{array}$ \\
\hline Cholesterol (mg/dL) & $\begin{array}{l}236.20 \\
\pm 70.35\end{array}$ & $\begin{array}{l}186.00 \\
\pm 42.59\end{array}$ & $\begin{array}{l}-45.05- \\
145.45 \\
(0.25)\end{array}$ \\
\hline $\begin{array}{l}\text { Triglyceride } \\
\text { (mg/dL) }\end{array}$ & $\begin{array}{l}204.00 \\
\pm 51.02 \\
\end{array}$ & $\begin{array}{l}134.00 \\
\pm 17.56\end{array}$ & $\begin{array}{l}6.15-133.84 \\
(0.036) \\
\end{array}$ \\
\hline $\begin{array}{l}\text { HDL } \\
(\mathrm{mg} / \mathrm{dL})\end{array}$ & $\begin{array}{l}54.00 \\
\pm 24.28 \\
\end{array}$ & $\begin{array}{l}48.00 \\
\pm 7.90 \\
\end{array}$ & $\begin{array}{l}-43.13-31.13 \\
(0.66)\end{array}$ \\
\hline $\begin{array}{l}\text { LDL } \\
(\mathbf{m g} / \mathbf{d L})\end{array}$ & $\begin{array}{l}108.25 \\
\pm 31.11\end{array}$ & $\begin{array}{l}154.80 \\
\pm 72.55\end{array}$ & $\begin{array}{l}-46.25- \\
139.35 \\
(0.27)\end{array}$ \\
\hline $\begin{array}{l}\text { HDL/LDL (above } \\
0.4)\end{array}$ & $0.38 \pm 0.22$ & $0.51 \pm 0.17$ & $\begin{array}{l}-0.456-0.20 \\
(0.394)\end{array}$ \\
\hline
\end{tabular}

Values were mean of the absolute result numbers $\pm \mathrm{SD}$, significant level was considered $<0.05,95 \%$ CI. FBG: fasting blood glucose, HOMA-IR: homeostatic model assessment for insulin resistance, HbA1c: hemoglobin A1c, HDL: high density lipoprotein, LDL: low density lipoprotein.

\section{Adverse reaction}

No hepatic or renal adverse effects were noted with any participant in the course of the study. One patient in group 1 suffered from hypoglycemia during the treatment period. No adverse effects were noted at the end of the research, and all participants proceeded with the study to its conclusion with no withdrawal.

\section{Discussion}

In the present study, fenugreek was provided to patients with type $2 \mathrm{DM}$ as adjuvant therapy in addition to the conventional antidiabetic medications. Fenugreek decreased the fasting blood sugar, although the reduction was not significant compared with glibenclamide. More interestingly, our results revealed a significant increase in fasting insulin level as well as an increase in the HDL/LDL ratio after administration of fenugreek for three months. Al- though it is not significant, fenugreek decreased the HOMA-IR, HbA1c, LDL, and triglyceride levels.

Consistent with our results, Sharma et al. ${ }^{10}$ and Xue et al. ${ }^{8}$ showed a steady decrease in triglycerides and LDL during a 24-week study period, with an in increase in HDL cholesterol. In our study, reducing the activity of LDL and increasing HDL and HDL/LDL indicated that the potential beneficial effect of fenugreek in preventing atherosclerosis and hyperlipidemia in patients with diabetes. However, more animal experiments, and larger clinical trials need to be done to confirm this observation.

Consistent with our study, Gupta et al. ${ }^{11}$ showed a nonsignificant difference between fenugreek and placebo groups regarding FBG, whereas fasting insulin release increased with an increase in insulin sensitivity as showed by HOMA-IR; serum triglycerides decreased, and HDL 
cholesterol increased significantly after 2 months. Mitra and Bhattacharya ${ }^{12}$ showed that fenugreek at higher doses decreased blood glucose and triglyceride levels and LDL and HDL cholesterol. Lu et al. ${ }^{13}$ concluded that fenugreek combined with sulfonylureas could lower the blood glucose level and ameliorate the clinical symptoms for the treatment of DM, and the therapy was relatively safe. In line with the present results, Kassaian et al. ${ }^{14}$ showed a decrease in FBS and triglycerides in 24 patients with type 2 DM placed on $10 \mathrm{~g} /$ day powdered fenugreek seeds mixed with yogurt or soaked in hot water for 8 weeks. In this study, glibenclamide in adjuvant with sulfonylureas significantly decreased HbA1c compared to fenugreek. $\mathrm{HbA1c}$ is the index of long-term glucose control. It has been shown that the $1 \%$ reduction in $\mathrm{HbA} 1 \mathrm{c}$ in diabetic patients decreased the risk of microvascular complications by 37\% \{Stratton, $2000 \# 1362\}$. Thus, our results indicate that glibenclamide could be more beneficial in preventing long-term DM complications. However, one must notice that the baseline $\mathrm{HbA1c}$ in glibenclamide group in this study has a lower level of HbA1c than fenugreek group.

The importance of our study is that it sheds some light on the mechanism of fenugreek on lowering blood glucose. Fenugreek significantly lowered serum insulin and HOMA-IR in patients on fenugreek for three months. Type 2 DM occurs due to insufficient supply of insulin from dysfunctional beta cells of the Islets of Langerhans of the pancreas. Insulin resistance occurs when the body cells fail to respond appropriately to the effects of insulin $^{15,16}$. Moreover, another mechanism of fenugreek in lowering blood glucose could be related to the high fiber content of fenugreek, either the total or mucilaginous fibers $^{12}$. Another reason for the blood glucose lowering effect may be related to the delayed gastric emptying that inhibits glucose transport and inhibits its absorption. Also, gastric emptying may be related to the galactomannan content of fenugreek that forms gel and also is responsible for lowering body weight.

\section{Conclusion}

The incidence of diabetes has been on the rise probably due to lifestyle changes that encourage sedentary lifestyles, lack of exercise, and aging. Herbal medication has gained much relevance in the recent past as an alternative therapy. Our study was conducted to determine the hy- poglycemic and hypolipidemic impacts of fenugreek seed on patients with type 2 DM. A $2 \mathrm{~g} /$ day dose of fenugreek for 12 weeks caused a significant increase in serum insulin and HDL/LDL ratio. Fenugreek did not cause any notable adverse effects on hepatic and renal functions throughout the study. Thus, fenugreek could be a beneficial adjuvant therapy in the glycemic control of patients with type 2 DM. However, larger scale clinical trials are needed to confirm those results.

\section{Study limitations}

The main limitation in the present study was the small number of the participants.

\section{Acknowledgments}

The authors highly acknowledge the participants in this study for their time. Also, the authors would like to thank Enago (www.enago.com) for the English language review.

\section{Author contributions}

(RAN): contributed to the study conceptualization and design, data collection, and drafting the manuscript. $(\mathrm{MMH})$ : contributed to the study conceptualization and design, data analysis, and critical revision of the paper. (FOK) and (RMM) contributed to data analysis, writing, and submission of the manuscript. All authors read and approved the final manuscript.

\section{Conflict of interest}

The authors declared that there is no conflict of interest.

\section{Funding}

This research was funded by King Abdulaziz city for science and technology.

\section{References}

1. WHO Organization. Diabetes Fact sheet 2017 [updated November 2017. Available from: http://www.who. int/mediacentre/factsheets/fs312/en/.(last access June 3, 2018)

2. Holt RIG, Cockram CS, Flyvbjerg A, Goldstein BJ. Textbook of diabetes. Fifth edition. ed. Chichester, West Sussex, UK ; Hoboken, NJ: Wiley-Blackwell; 2016.

3. Ball MJ. Healthcare information management systems : a practical guide. $2^{\text {nd }}$ ed. New York: Springer-Verlag; 1995. 4. Otoom SA, Al-Safi SA, Kerem ZK, Alkofahi A. The 
use of medicinal herbs by diabeticjordanian patients. $J$ Herb Pharmacother. 2006; 6 (2):31-41.

5. Ali-Shtayeh MS, Jamous RM. Complementary and alternative medicine use amongst Palestinian diabetic patients. Complement Ther Clin Pract. 2012; 18 (1):16-21.

6. Kamel F, Magadmi R, Hagras M, Magadmi B, AlAhmad R. Knowledge, attitude, and beliefs toward traditional herbal medicine use among diabetics in Jeddah Saudi Arabia. Complementary Therapies in Clinical Practice. 2017; 29:207-212

7. Hannan JM, Ali L, Rokeya B, Khaleque J, Akhter M, Flatt PR, et al. Soluble dietary fibre fraction of Trigonella foenum-graecum (fenugreek) seed improves glucose homeostasis in animal models of type 1 and type 2 diabetes by delaying carbohydrate digestion and absorption, and enhancing insulin action. Br J Nutr. 2007; 97 (3):514-521. 8. Xue WL, Li XS, Zhang J, Liu YH, Wang ZL, Zhang RJ. Effect of Trigonella foenum-graecum (fenugreek) extract on blood glucose, blood lipid and hemorheological properties in streptozotocin-induced diabetic rats. Asia Pac J Clin Nutr. 2007; 16 Suppl 1:422-426.

9. Sanofi-aventis new zealand limited. Daonil $5 \mathrm{mg}$ tablets data sheet. 2017. http://www.medsafe.govt.nz/profs/ Datasheet/d/Daoniltab.pdf. (last access June 3, 2018) 10. Sharma RD, Sarkar A, Hazra DK, Misra B, Singh JB, Maheshwari BB, Sharma SK. Hypolipidaemic Effect of Fenugreek Seeds: a Chronic Study in Non-insulin De- pendent Diabetic Patients. Phytotherapy Research. 1996; 10 (4):332-334.

11. Gupta A, Gupta R, Lal B. Effect of Trigonella foenum-graecum (fenugreek) seeds on glycaemic control and insulin resistance in type 2 diabetes mellitus: a double blind placebo controlled study. J Assoc Physicians India. 2001; 49:1057-1061. PubMed.

12. Mitra AB, D. Dose-dependent effects of Fenugreek composite in Diabetes with dislipidaemia. Internet Journal of Food Safety. 2006; 8:49-55.

13. Lu FR, Shen L, Qin Y, Gao L, Li H, Dai Y. Clinical observation on trigonella foenum-graecum L. total saponins in combination with sulfonylureas in the treatment of type 2 diabetes mellitus. Chin J Integr Med. 2008; 14 (1):56-60. PubMed.

14. Kassaian N, Azadbakht L, Forghani B, Amini M. Effect of fenugreek seeds on blood glucose and lipid profiles in type 2 diabetic patients. Int J Vitam Nutr Res. 2009; 79 (1):34-39.

15. Stratton IM, Adler AI, Neil HA, Matthews DR, Manley SE, Cull CA, et al. Association of glycaemia with macrovascular and microvascular complications of type 2 diabetes (UKPDS 35): prospective observational study. BMJ. 2000; 321 (7258):405-412.

16. Vora JB, John. Evidence-based Management of Diabetes. 1 ed: tfm Publishing Ltd; 2012. 522 p.

17. Shaw KC, Michael. Diabetes: Chronic Complications. $3^{\text {rd }}$ ed: John Wiley \& Sons, Ltd.; 2012. 